\title{
Mass treatment of trachoma with azithromycin 1.5\% eye drops in the Republic of Cameroon: feasibility, tolerance and effectiveness
}

\author{
P Huguet, ${ }^{1}$ L Bella, ${ }^{2}$ E M Einterz, ${ }^{3}$ P Goldschmidt, ${ }^{4}$ P Bensaid ${ }^{5}$
}

${ }^{1} \mathrm{NMH} / \mathrm{CPM} / \mathrm{PBD}$, World Health Organization, Geneva,

Switzerland ${ }^{2}$ Ministry of Health, Yaounde, Republic of Cameroon ${ }^{3}$ Kolofata District Health Service, Kolofata, Republic of Cameroon ${ }^{4}$ Laboratoire du Centre National d'Ophtalmologie des Quinze Vingts, Paris, France ${ }^{5}$ Ophtalmo Sans Frontières, Luçon, France

\section{Correspondence to} Dr P Huguet, World Health Organization, Avenue Appia, 20, 1211 Geneva 27, Switzerland; p.huguet@laboratoires-thea.fr

Accepted 26 June 2009 Published Online First 18 August 2009
This paper is freely available online under the BMJ Journals unlocked scheme, see http://bjo. bmj.com/site/about/unlocked. xhtml.

\section{ABSTRACT}

Aims An epidemiological study carried out in 2006 indicated a high prevalence of blinding trachoma in the Kolofata Health District, Far North Region, Republic of Cameroon. As a result, the national blindness control programme of Cameroon instituted a trachoma elimination programme using the SAFE strategy. Methods A campaign to treat the entire district population with azithromycin $1.5 \%$ eye drops was undertaken in February 2008. To measure the effectiveness of treatment on the prevalence of active trachoma, two epidemiological studies were conducted on a representative sample of children aged between 1 and 10 years. The first study was performed just prior to the treatment campaign and the second study was performed 1 year later.

Results The prevalence of active forms of trachoma (trachomatous inflammation-follicular (TF) + TF/ trachomatous inflammation-intense (TI)) dropped from 31.5 (95\% Cl 26.4 to 37.5 )\% before treatment to 6.3 (95\% Cl 4.1 to 9.6$) \% 1$ year after treatment-a reduction of nearly $80 \%$. There were no reports of serious or systemic side effects. Tolerance was excellent and no treatment was interrupted.

Conclusion Mass treatment with azithromycin 1.5\% eye drops is feasible, well tolerated and effective.

Prevention of blindness and visual impairment is one of the public health priorities of the Republic of Cameroon. The National Blindness Prevention Programme and a Vision 2020 plan were established as a result of this policy of prevention. A study to evaluate the prevalence of active and scarring trachoma, conducted in December 2006 in the Kolofata Health District (figure 1), signalled the presence of endemic trachoma with significant blinding potential. ${ }^{1}$ The National Program of Prevention of Blindness decided to plan a elimination programme by implementing the Surgery-Antibiotics-Facial cleanliness-Environmental impact (SAFE) strategy ${ }^{2}$ and addressing the " $\mathrm{A}$ " (antibiotic) component, a mass treatment of the entire population of the district with azithromycin $1.5 \%$ eye drops.

The objective of this study was to assess the feasibility, tolerance and effectiveness of a topical treatment with azithromycin $1.5 \%$ eye drops, used for the first time on a large scale to reduce the prevalence of active forms of trachoma in a population.

\section{METHODS}

\section{Mass treatment campaign}

In accordance with the WHO recommendations, ${ }^{3}$ the trachoma control programme in the Kolofata
Health District called for one mass treatment campaign per year for 3 years. The first campaign began on 23 February 2008 and ended on 10 March 2008.

The target population was all 115274 residents of the Kolofata Health District. ${ }^{4}$

A total of 120000 complete treatments $(720000$ single doses) of azithromycin $1.5 \%$, donated by Théa Laboratories (Clermont-Ferrand, France), were sent by air from Europe to Yaoundé (Cameroon), and by train from Yaoundé to Kolofata.

A door-to-door strategy was used. In each compound (group of shelters housing an extended family), a local community health worker, helped by a literate second-level community health worker, performed a census of the entire population of the neighbourhood or village assigned to the local community health worker. One census form was completed for each compound.

Over the following days, an effort was made to treat the entire population of the district with azithromycin $1.5 \%$ eye drops, one drop in each eye in the morning and evening for three consecutive days (six doses). Questionnaires designed to document side effects or symptoms of intolerance to the eye drops were administered and collected daily by ophthalmology nurses.

In all, 250 local community health workers, 23 second-level community health workers, one head nurse for each of the seven health centres, two District Health Service logisticians and four ophthalmology nurses from the non-governmental organisation Ophtalmo Sans Frontières were involved in the campaign. The Kolofata District Medical Officer and an expert from the National Centre of Ophthalmology of the Quinze Vingts, Paris, coordinated and supervised all activities related to training, logistics, education and treatment.

\section{The studies}

Two descriptive cross-sectional studies were conducted in the Kolofata Health District, the first 15 days prior to treatment in February 2008 and the second 1 year after treatment in January 2009. These studies were performed in order to measure the effectiveness of treatment on the prevalence of active forms of trachoma in the population. Trachomatous inflammation-follicular (TF) and $\mathrm{TF} /$ trachomatous inflammation-intense (TI) forms among children aged between 1 and 10 years were used as indicators. The standard WHO protocol for trachoma prevalence surveys was used. $^{5}$ 


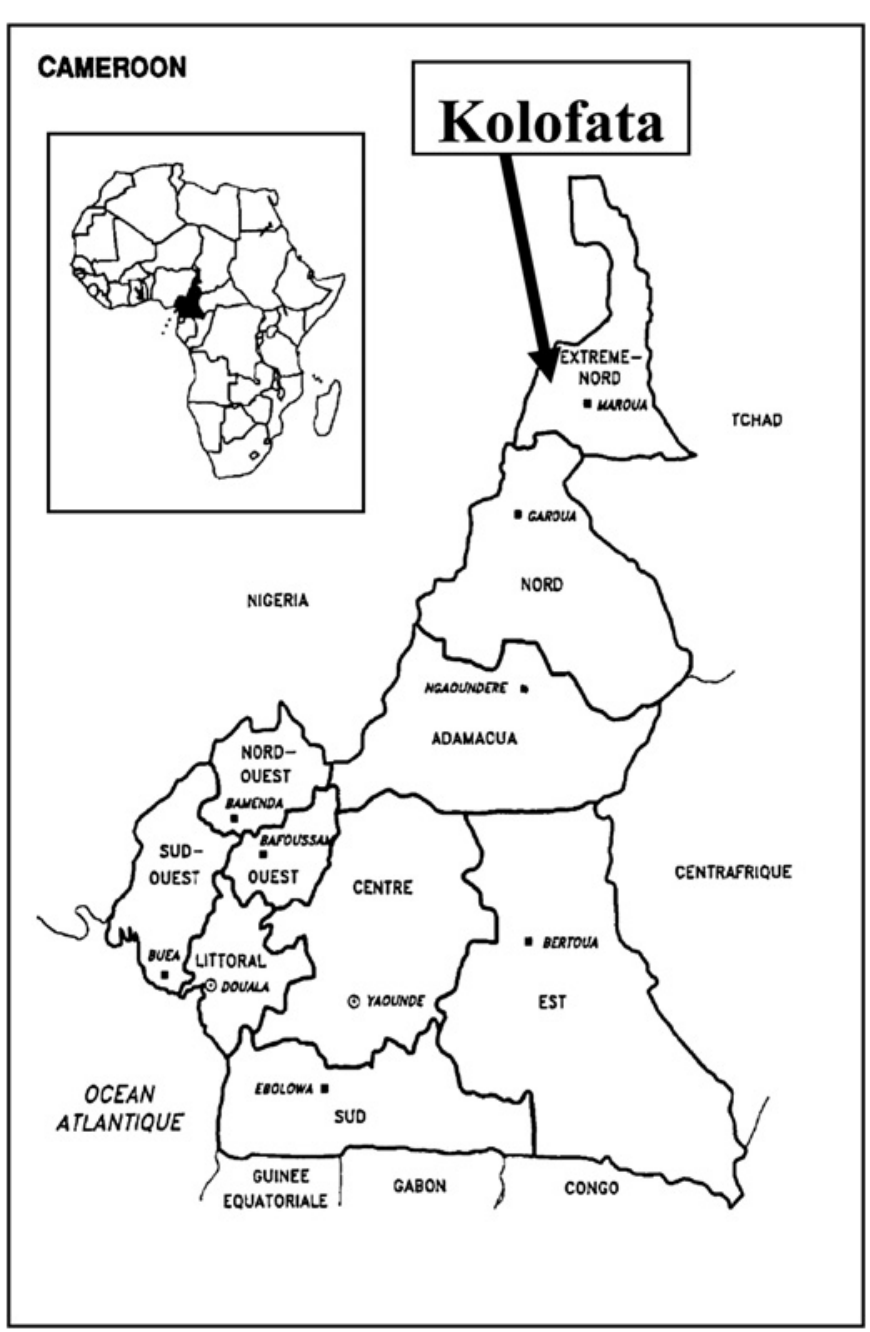

Figure 1 Map of the Republic of Cameroon.

The population studied was chosen at random and was based on the exhaustive list of villages and demographic statistics gathered in 2006 for the national census. ${ }^{4}$

Assuming a prevalence of $<5 \%$ following the third year of mass treatment, it was necessary to include 2400 children in the study to obtain a precision of approximately $1.5 \%$ at a bilateral alpha threshold of $5 \%$ and a cluster effect of $4 .{ }^{6}$ This would also allow conclusions to be drawn, in accordance with WHO recommendations, concerning the interruption of transmission. ${ }^{3}$ As a result, 2400 children aged between 1 and 10 years were divided into 40 clusters, with 60 children per cluster. The WHO simplified grading system was used for the recognition and registering of cases of trachoma. ${ }^{7}$

Two teams shared the fieldwork. Each team consisted of a census nurse and either an ophthalmology nurse or an ophthalmologist. The same teams and the same ophthalmologist conducted the before-treatment study and the after-treatment study. A 4-day training session was held for the nurses. After these training sessions, the inter-observer variation was very satisfactory $(\kappa=0.81-1.00)$. Data were compiled and analysed using EPINFO 6 software (Centers for Disease Control and Prevention, Atlanta, Georgia, USA). Estimated CIs took into account the composition of sample clusters using the Epitable program from EPIINFO $6 .^{8}$

\section{RESULTS}

Results of the mass treatment campaign using azithromycin $1.5 \%$ eye drops

Each of the 250 local community health workers was assigned a village or neighbourhood of 400 to 500 residents. During the 15 days preceding the beginning of treatment, the local community health workers, helped by a literate second-level community health worker, conducted an exhaustive door-to-door census of all residents of the Kolofata Health District. The local community health workers then administered treatment by visiting each household in the morning and evening for three consecutive days.

There were 115274 people counted in the census; community health workers administered azithromycin $1.5 \%$ eye drops (one drop in each eye in the morning and evening for 3 days) to 111 340 people (coverage $96.6 \%$ ). The campaign covered the entire district and lasted 15 days. A total of 51659 adults and 59681 children $<15$ years old were treated (52 866 male and 58474 female). Two adults refused treatment for personal reasons not linked to the treatment.

Questionnaires concerning any side effects of treatment were administered by ophthalmology nurses during daily visits to assigned villages. Minor complaints were recorded (blurred vision lasting several minutes following instillation of eye drops or transient burning sensation in the eyes). No adult requested that treatment for themselves or their children be interrupted. There were no reported serious or systemic side effects.

Age and sex distribution of children in the study population aged between 1 and 10 years

The number of children examined during the study relative to the number counted in the census is presented in table 1.

Age and sex distributions were similar in the sample populations before and after treatment $(p>0.05)$ (table 2).

\section{Prevalence of trachoma before and after treatment among children aged between 1 and $\mathbf{1 0}$ years}

The prevalence of TF in the study sample was estimated to be 24 (95\% CI 20.7 to 27.5$) \%$ before treatment and 5.8 (95\% CI 4.1 to 8) $\%$ after treatment (table 3 ). The prevalence of TF/TI was estimated to be 7.5 (95\% CI 5.7 to 10$) \%$ before treatment and 0.5 (95\% CI 0.13 to 1.6$) \%$ after treatment (table 3 ). The prevalence of active forms (TF + TF/TI) was estimated to be 31.5 (95\% CI 26.4 to 37.5$) \%$ before treatment and 6.3 (95\% CI 4.5 to 8.6$) \%$ after treatment (table 3$)$. The OR for TF before and after treatment was 5.1 (range 4.2-6.2). The OR was 14 (range 8.1-24) for TI forms and 6.7 (range 5.6-8.1) for TF + TF/TI forms.

\section{DISCUSSION}

There are currently two ways of assessing the epidemiological situation in a trachoma endemic area: the nucleic acid amplification tests and the clinical grading. The WHO trachoma simplified grading system is currently the only WHO-recommended system to assess the clinical trachoma prevalence and to

Table 1 Study participation

\begin{tabular}{|c|c|c|c|c|c|c|}
\hline & \multicolumn{2}{|c|}{ Examined (n) } & \multicolumn{2}{|c|}{ Counted (n) } & \multicolumn{2}{|c|}{ Participation (\%) } \\
\hline & $\begin{array}{l}\text { Before } \\
\text { treatment }\end{array}$ & $\begin{array}{l}\text { After } \\
\text { treatment }\end{array}$ & $\begin{array}{l}\text { Before } \\
\text { treatment }\end{array}$ & $\begin{array}{l}\text { After } \\
\text { treatment }\end{array}$ & $\begin{array}{l}\text { Before } \\
\text { treatment }\end{array}$ & $\begin{array}{l}\text { After } \\
\text { treatment }\end{array}$ \\
\hline $\begin{array}{l}\text { Children } \\
\text { aged }>1 \\
\text { and }<10 \\
\text { years }\end{array}$ & 2517 & 2404 & 2570 & 2411 & 97.9 & 99.7 \\
\hline
\end{tabular}


Table 2 Comparison of the distribution of children included in the study in 2008 and 2009 by age and sex

\begin{tabular}{lll}
\hline \multirow{2}{*}{ Variable } & Sample & \\
\cline { 2 - 3 } & Before treatment & After treatment \\
\hline Age 1-4 years & $1391(55.3)$ & $1332(55.4)$ \\
Age 5-9 years & $1126(44.7)$ & $1072(44.6)$ \\
Male & $1280(50.9)$ & $1236(51.4)$ \\
Female & $1237(49.1)$ & $1169(48.6)$ \\
Total & $2517(100)$ & $2404(100)$ \\
\hline
\end{tabular}

Values are $n(\%)$.

monitor a trachoma control programme in a community. ${ }^{9}$ We therefore decided to use it to assess the feasibility, tolerance and effectiveness of a topical treatment with azithromycin $1.5 \%$ eye drops, used for the first time on a large scale to reduce the prevalence of active forms of trachoma in a population.

Feasibility of mass treatment with azithromycin $\mathbf{1 . 5 \%}$ eye drops A high coverage $(96.6 \%$ of the census population) was obtained as a result of treatment being administered directly by the health personnel who participated in the campaign. The campaign required the mobilisation of all the district's community health workers for 15 days. Daily supervision in the field as well as highquality coordination by the health service authorities were indispensable, as these prevented interruptions in the supply of eye drops and assured the daily collection of data relating to treatment coverage and side effects.

Tolerance of mass treatment with azithromycin $1.5 \%$ eye drops Apart from minor complaints, which did not result in treatment interruption, treatment was accepted and well tolerated by both children and adults.

\section{Results of mass treatment with azithromycin $1.5 \%$ eye drops}

The importance of the endemic trachoma in this district justified the mass treatment of the entire district population with azithromycin $1.5 \%$ eye drops as part of the SAFE strategy and in accordance with WHO recommendations. ${ }^{3}$

The reduction of the prevalence of active trachoma among children is likely to be mainly a result of the mass treatment with azithromycin $1.5 \%$ eye drops. Between the first study conducted in 2006 and the study conducted prior to the first treatment in 2008, there was no significant reduction of trachoma prevalence, which might have been due to a "secular trend" effect. Between February 2008 and January 2009, the application of the other components of the SAFE strategy consisted of the construction of a borehole water pump to provide safe water in each of three villages and the undertaking of numerous educational activities to promote individual and collective hygiene, but it seems unlikely that these other interventions alone could have produced so large a reduction in trachoma prevalence in so short a time.
Relative effectiveness of azithromycin $1.5 \%$ eye drops and oral azithromycin

The most common drugs currently used in trachoma mass treatment campaigns are azithromycin $20 \mathrm{mg} / \mathrm{kg}$ taken orally and tetracycline $1 \%$ eye ointment.

In Niger, a mass treatment campaign using oral azithromycin was conducted in two districts with 72 villages from 2002 to 2005. The prevalence of TF among children decreased from $62.3 \%$ and $49.5 \%$ to $7.6 \%$ and $6.7 \%$ in 3 years, ${ }^{10}$ a reduction of $89 \%$ in one village and $85 \%$ in the other. No study was conducted within the 3-year interval. In Mali, a mass treatment campaign using oral azithromycin was conducted in seven districts from 2002 to 2005 . The prevalence of TF/TI among children decreased from $33 \%$ to $2.5 \%$ in 3 years, ${ }^{11}$ a reduction of $92.4 \%$.

Since prevalence rates 1 year after treatment with oral azithromycin are unknown, it is not yet possible to conclude with certainty that mass treatment with azithromycin $1.5 \%$ eye drops can be considered at least as effective as treatment with oral azithromycin. We await the results of studies planned for 2010 and eventually 2011 following the third of three consecutive annual treatment campaigns for confirmation.

A clinical trial showed that azithromycin $1.5 \%$ twice a day for 3 days has a similar efficacy to a single oral $20 \mathrm{mg} / \mathrm{kg}$ dose of azithromycin for the treatment of active trachoma in children 2 months after treatment. ${ }^{12}$ There are no publications on the relative effectiveness of tetracycline $1 \%$ eye ointment and azithromycin $1.5 \%$ eye drops on active trachoma.

\section{Potential advantages of topical azithromycin over topical tetracycline and oral azithromycin}

In 1997, a working paper pointing out the need for a topical treatment was presented at the WHO Alliance for the Global Elimination of Blinding Trachoma by the Year 2020 (GET 2020) meeting. ${ }^{13}$ This paper also listed the potential advantages of topical azithromycin over topical tetracycline and oral azithromycin.

In children with active trachoma, topical tetracycline ointment can be difficult to apply and compliance is poor. The ointment may cause discomfort and blurred vision. Many children who are asymptomatic may not continue the topical treatment, and parents may not be motivated to continue such therapy. The lack of compliance with topical tetracycline ointment may account for the failure to control trachoma as a major cause of blindness worldwide. ${ }^{14}$

Cases of entropion trichiasis detected during the investigating teams' visits to the villages were referred to the ophthalmological service of the Kolofata District Hospital for free surgery. The same was true of cases detected by community health workers during treatment and education campaigns. From January 2007 to December 2008, nearly 1000 eyelids affected by entropion trichiasis were surgically repaired.

Following encouraging results from the first mass treatment campaign with azithromycin $1.5 \%$ eye drops, two additional mass treatment campaigns were planned. The second campaign took place in February 2009. A third study to track the evolution

Table 3 Prevalence of active trachoma (TF, TF/TI and TF + TF/TI) before and after treatment among children aged between 1 and 10 years

\begin{tabular}{|c|c|c|c|c|c|c|}
\hline & \multicolumn{2}{|l|}{ TF } & \multicolumn{2}{|c|}{$\mathrm{TF} / \mathrm{TI}$} & \multicolumn{2}{|c|}{$\mathrm{TF}+\mathrm{TF} / \mathrm{TI}$} \\
\hline & $\mathrm{n}$ & $\%(95 \% \mathrm{CI})$ & $\mathrm{n}$ & $\%(95 \%$ CI) & $\bar{n}$ & $\%(95 \%$ Cl) \\
\hline Before treatment & 603 & $24(20.7$ to 27.5$)$ & 190 & $7.5(5.7$ to 10$)$ & 793 & 31.5 (26.4 to 37.5$)$ \\
\hline After treatment & 140 & 5.8 (4.1 to 8 ) & 14 & 0.5 (0.13 to 1.6$)$ & 154 & $6.4(4.5$ to 8.6$)$ \\
\hline
\end{tabular}

$\mathrm{TF}$, trachomatous inflammation-follicular; $\mathrm{Tl}$, trachomatous inflammation-intense. 
of active trachoma prevalence among children is planned for January 2010 prior to the proposed third mass treatment campaign.

To reinforce and perpetuate the reduction of trachoma prevalence and to advance towards elimination of blinding trachoma in this area, the other three components of the SAFE strategy must also be reinforced as recommended by GET 2020. ${ }^{2}$ Furthermore, it would be advisable to proceed to a rapid evaluation of the prevalence of trachoma in the North and Far North Regions in order to understand the geographical extent of the trachoma endemic in Cameroon. If the endemic is widespread, the success of this first trachoma treatment campaign should be extended to the entire North and Far North Regions of Cameroon.

Acknowledgements This study benefited from the expertise of the WHO Prevention of Blindness and Deafness Unit. The Ministry of Health of Cameroon placed at our disposal the personnel necessary for the success of this study. The authors also thank Kolofata's traditional chiefs and heads of households for their hospitality and participation.

Funding The prevalence surveys were financed by Ophtalmo sans Frontières. Théa Laboratories donated the azithromycin $1.5 \%$ eye drops.

Competing interests None declared.

Ethics approval The treatment plan received authorisation from the Cameroon Ministry of Public Health in February 2008.

Patient consent Informed consent was systematically requested from parents of minors and indicated by signature or fingerprint.

Provenance and peer review Not commissioned; externally peer reviewed.

\section{REFERENCES}

1. Bensaid $\mathbf{P}$, Huguet $P$, Goldschmidt $P$, et al. Epidemiological survey of trachoma in the Kolofata district, Far North Province, Cameroon. Rev Int Trach Pathol Ocul Trop Subtrop santé Publique 2007;84:79-103.

2. World Health Organization. The SAFE strategy. Preventing trachoma: a guide for environmental sanitation and improved hygiene. WHO/PBD/00.7Rev1. Geneva: World Health Organization, 2001.

3. World Health Organization. Report of the eighth meeting of the WHO Alliance for the Global Elimination of Blinding Trachoma. Report of a WHO Working Group. WHO/ PBD/GET/04.2. Geneva: World Health Organization, 2004.

4. National Institute of Statistics. Third General Census of the population and households of Cameroon. Yaounde: National Institute of Statistics, 2005

5. World Health Organization. Primary health care level management of trachoma WHO/PBL 93.33. Geneva: World Health Organization, 1993.

6. Katz I, Zeger SL, Tielsch JM. Village and household clustering of xerophthalmia and trachoma. Int J Epidemiol 1988;17:86-9.

7. Thylefors B, Dawson CR, Jones BR, et al. A simple system for the assessment of trachoma and its complications. Bull Org Mond Santé 1987;65:477-83.

8. Cochran WG. Sampling techniques. 3rd edn. New York: Wiley, 1977.

9. World Health Organization. Report of the Second Global Scientific Meeting of the WHO Alliance for the Global Elimination of Blinding Trachoma. Report of a WHO Working Group. WHO/PBD/GET/03.1. Geneva: World Health Organization, 2003.

10. Amza A. Résultats après trois années de mise en œuvre de la stratégie CHANCE dans la Région de Zinder au Niger. Rev Int Trach Pathol Ocul Trop Subtrop santé Publique 2006;83:103-14.

11. Bamani S. La lutte contre le trachome au Mali: forces et faiblesses. Rev Int Trach Pathol Ocul Trop Subtrop santé Publique 2006;83:114-27

12. Cochereau I, Goldschmidt P, Goepogui A, et al. Efficacy and safety of short duration azithromycin eye drops versus azithromycin single oral dose for the treatment of trachoma in children: a randomised, controlled, double-masked clinical trial. $\mathrm{Br} \mathrm{J}$ Ophthalmol 2007;91:667-72.

13. World Health Organization. Report of the first meeting of the WHO Alliance for the Global Elimination of Trachoma. WHO/PBL/GET/97.1. Geneva: World Health Organization, 1997.

14. Tabbara KF, Abu-el-Asrar A, al Omar 0, et al. Single-dose azithromycin in treatment of trachoma. A randomized, controlled study. Ophthalmology 1996:10:828-46. 